\title{
Políticas, epidemiologia e práxis no Sistema Único de Saúde
}

\author{
Policies, epidemiology, and praxis in Brazil's Unified National \\ Health System
}

\author{
Políticas, epidemiologia y praxis en el Sistema Único de \\ Salud brasileño
}

POLÍTICAS, EPIDEMIOLOGIA E EXPERIÊNCIAS NO SISTEMA ÚNICO DE SAÚDE (SUS): POSSIBILIDADES E DESAFIOS DO CENÁRIO BRASILEIRO. Silva Júnior FJG, Sales JCS, Galiza FT, Monteiro CFS, organizadores. Curitiba: Editora CRV; 2020. 474 p. ISBN: 978-65-5578-792-4.

doi: 10.1590/0102-311X00295120

Na sociedade brasileira, as questões econômicas, sociais e ambientais são regulamentadas por políticas públicas 1 , as quais podem ser entendidas como um dispositivo que revela o dever do Estado em garantir, no âmbito da saúde, a resolutividade dos serviços, o acesso oportuno à assistência e ao cuidado. Políticas públicas têm no cerne de sua criação a razão de ampliar a capacidade do sistema em acolher as necessidades de saúde e, ao mesmo tempo, reorganizar as práticas 2,3 .

As principais características do sistema de saúde brasileiro têm raízes no início do século passado, em decorrência de uma proposta estatutária. Em 1988, a Constituição Federal reconheceu a saúde como um direito do cidadão e um dever do Estado, inserida em uma concepção ampla de seguridade social pela instituição do Sistema Único de Saúde (SUS). A Constituição Federal assegura que as políticas de saúde sejam orientadas pelos princípios e diretrizes do SUS, contrapondo-se à tradição histórica de como as mesmas têm sido estabelecidas. Tais políticas têm apresentado uma configuração altamente centralizada e verticalizada, com concentração do poder no nível central de governo, frente à definição de prioridades e da execução dos serviços de saúde pelos estados e municípios ${ }^{4}$. Ressalta-se que políticas de saúde, quer na sua formulação, quer na sua implantação e execução, configuram processos complexos e jogos de interesses múltiplos à guisa das reais necessidades de saúde da população. O caráter pluralístico do processo de gestão das políticas públicas traz consigo o papel do Estado, a fim de fortalecer sua dimensão articuladora e catalisadora na exequibilidade deste processo ${ }^{3}$.

O Brasil é o único país do mundo com mais de 209 milhões de brasileiros que mantém um sistema de saúde público, universal, integral, características que aliadas às suas dimensões continentais e às suas desigualdades regionais acarretam inúmeros desafios à consolidação deste sistema. Um desses desafios é decorrente da transição demográfica acelerada e epidemiológica expressas por uma situação de tripla carga de doenças: (1) a agenda não superada de doenças infecciosas e carenciais; (2) o aumento das causas externas; e (3) a presença hegemônica de condições crônicas 5 . Tal panorama sintetiza uma situação de saúde que não poderá ser respondida adequadamente por um sistema de atenção à saúde ainda demasiadamente fragmentado, reativo, episódico e voltado prioritariamente para o enfrentamento das condições agudas e das agudizações das condições crônicas, cujo 
lócus privilegiado do modelo assistencial ainda é o hospital 5.

A análise da situação atual do SUS é uma tarefa que exige, em primeiro lugar, o reconhecimento da complexidade do processo político, do desenvolvimento organizacional e da reorientação dos processos de trabalho nos diferentes níveis de gestão do sistema. Observa-se uma tendência à diversificação das estratégias utilizadas pelos dirigentes do sistema em cada conjuntura, em um processo contínuo de ajuste das propostas às possibilidades de ação e dos constrangimentos decorrentes da permanente negociação com os diversos atores políticos envolvidos, sejam os que atuam internamente no sistema, sejam os que pressionam o sistema de fora, buscando que as decisões adotadas atendam a seus interesses e necessidades 4,6 .

Há que se considerar que o SUS demanda, sobretudo, uma busca por sustentabilidade tanto institucional quanto política 4 . A sustentabilidade institucional, para além do financiamento, impõe experimentar novas conformações institucionais que superem as limitações impostas pelos mercado, burocracia, partidarismo e clientelismo político 6 . A sustentabilidade política exige a construção de um bloco histórico com engajamento de forças que atravesse a sociedade civil e o Estado, envolvendo entidades como as que integram o Fórum da Reforma Sanitária Brasileira, o Ministério Público, o Ministério e as Secretarias Estaduais e Municipais de Saúde, o Parlamento, entre outros, em defesa do SUS e da Reforma Sanitária Brasileira, implicando a ampliação da consciência social acerca dos direitos e a permanente mobilização em torno da ampliação de suas bases sociais de apoio e de legitimação 4,6. Nesse sentido, é premente defender o SUS, é preciso garantir sustentação política e financeira suficiente para sua plena atuação, agindo, inclusive de forma intersetorial, na promoção, prevenção e recuperação de agravos à saúde. Compreender o processo de construção, os indicadores de serviço e saúde, e refletir sobre as experiências do sistema de saúde público brasileiro são essenciais para que possamos melhor conhecê-lo, e assim poder defendê-lo e aprimorá-lo com propriedade. A obra Políticas, Epidemiologia e Experiências no Sistema Único de Saúde (SUS): Possibilidades e Desafios do Cenário Brasileiro 7 , recentemente publicada em outubro de 2020, faz exatamente esse exercício.

O livro compartilhado por muitos sujeitos que se reconhecem nesses campos e se autorizam como autores de suas existências por meio de capítulos de livro, experiências, apresenta uma obra coletiva que pode ser olhada como uma transversal no tempo, trazendo perplexidade ao reviver o SUS como uma política em movimento e afirmar nosso protagonismo, ao mesmo tempo em que serve de linha de base para refletirmos sobre o quanto, como e para onde vão nossos movimentos.

O livro está organizado em três partes que conversam harmonicamente entre si, trazendo aspectos importantes do SUS. A Parte I, intitulada O Processo de Construção do Sistema Único de Saúde: Perspectiva Política, tem 8 capítulos que delineiam sob uma perspectiva política o processo de construção do SUS, trazendo ao debate a atualização histórica dos princípios doutrinários do SUS e os desafios políticos e organizacionais de um sistema de atenção à saúde sob gestão única, descentralizada com participação social. Como política social coerente com o direito constitucional à saúde, o SUS apresenta contemporaneamente possibilidades e desafios decorrentes da eclosão de vozes de segmentos sociais que deixam a invisibilidade, vocalizam suas necessidades e suscitam políticas emergentes. Trata-se, portanto, de um resgate histórico e uma avaliação crítica do SUS e das políticas de saúde vinculadas a ele, além de analisar as perspectivas e desafios na contemporaneidade e futuros.

A Parte II, denominada Estudos Epidemiológicos no Sistema Único de Saúde, conta com 16 capítulos, nos quais são apresentados estudos epidemiológicos no SUS. De fato, é a parte em que mais nitidamente se percebe o quanto a Epidemiologia avançou seus limites epistemológicos e possibilitou interfaces nas quais as informações produzidas permitem a visibilidade da situação de saúde, apontando critérios e indicadores para a formulação de políticas e protocolos de avaliação e controle social. Reúne capítulos sobre a capacidade funcional de idosos com hanseníase, importância de registros de câncer no contexto da Vigilância em Saúde, conhecimento e desafios que se encontram no conhecimento e práticas profissionais em biossegurança, conservação de imunobiológicos, artes digitais e prevenção de agravos à saúde de profissionais de saúde e os efeitos de práticas educativas no autocuidado de populações vulneráveis.

O livro encerra na Parte III, intitulada Reflexões e Experiências no Sistema Único de Saúde, que abarca 11 capítulos que contemplam reflexões e experiências no SUS desenvolvidas em diversos 
territórios, com diferentes atores em diversos níveis de atenção, demonstrando que os serviços de saúde são cenários de problemas complexos e não estruturados que suscitam conhecimento e experiências que resultem em intervenções efetivas e eficazes. São experiências que compreendem desde reflexões sobre conceitos fundantes para um agir educativo na saúde, a utilização de tecnologias leves e relacionais que tornam produtivo o encontro que ocorre entre profissional nas unidades de saúde, a processos que se materializam em ato no trabalho vivo em saúde. Nesse plano, Epidemiologia e Política de Saúde interagem e se concretizam nas formas como se organizam conhecimentos, tecnologia e recursos humanos na produção e oferta de cuidados às coletividades.

Ao final de cada capítulo, nas três partes do livro, são exibidas questões reflexivas e encaminhamentos possíveis para a transformação da práxis. Nesse sentido, a obra aqui descrita se dirige a todos e todas nós, profissionais de saúde, docentes, pesquisadores, discentes e usuários, sensibilizando e despertando o sentido de pertencimento a um contexto histórico que nos conduz ao compromisso com a saúde, com o outro e com o SUS, e nos convida a prosseguir motivados por cada capítulo, na defesa da consolidação do SUS como um sistema universal de saúde. A leitura desta publicação sinaliza para um olhar crítico, construtivo e criativo sobre uma realidade construto de ações humanas. Assim, o presente livro é, de certa forma, uma ode ao SUS, nos fazendo refletir sobre a sua relevância para nossa sociedade. Urge combater os desmontes, as ameaças visíveis e veladas a esse sistema de saúde que tanto nos oferece.

Luis Carlos Lopes-Júnior 1

1 Universidade Federal do Espírito Santo, Vitória, Brasil. lopesjr.lc@gmail.com

\section{Informação adicional}

ORCID: Luis Carlos Lopes-Júnior (0000-00022424-6510).

1. Lucchese PTR, coordenadora. Políticas públicas em saúde pública. São Paulo: Centro Latino-Americano e do Caribe de Informação em Ciências da Saúde; 2002.

2. Righi LB, Pasche DF, Akermam M. Saúde e desenvolvimento: interconexões, re-orientação dos serviços de saúde e desenvolvimento regional. http://portal.saude.gov.br/portal/ar quivos/pdf/avaliacao_saude_desenvolvimento. pdf.

3. Cohn A. O estudo das políticas de saúde: implicações e fatos. In: Campos GWS, Bonfim JRA, Minayo MCS, Akerman M, Drumond Júnior M, Carvalho YM, organizadores. Tratado de Saúde Coletiva. Rio de Janeiro: Editora Fiocruz; 2012. p. 219-46.

4. Paim J, Travassos C, Almeida C, Bahia L, Macinko J. The Brazilian health system: history, advances, and challenges. Lancet 2011; 377:1778-97.

5. Mendes EV. As redes de atenção à saúde. 2a Ed. Brasília: Organização Pan-Americana da Saúde; 2011.

6. Castro MC, Massuda A, Almeida G, MenezesFilho NA, Andrade MV, de Souza Noronha KVM, et al. Brazil's unified health system: the first 30 years and prospects for the future. Lancet 2019; 394:345-56.

7. Silva Júnior FJG, Sales JCS, Galiza FT, Monteiro CFS, organizadores. Políticas, epidemiologia e experiências no Sistema Único de Saúde (SUS): possibilidades e desafios do cenário brasileiro. Curitiba: Editora CRV; 2020.

Recebido em 13/Out/2020

Aprovado em 19/Out/2020 